\title{
COMMENTARY
}

\section{Would Indian Agriculture Benefit from a Stewardship Model?}

\author{
Ravi Prabhu*
}

\begin{abstract}
Indian agriculture perpetuates - and therefore must reckon with numerous threats to ecological, economic and social sustainability. These arise for the most part from the commodification of nature and the reliance on external inputs into increasingly industrialized forms of agriculture. Low external input agriculture like agroforestry, regenerative agriculture, and the like, are viable alternatives that are more likely to deliver outcomes suitable to the structure of Indian agriculture. However, they too depend on the commodification of nature as the sole source of economic framing. An alternate framing, the Stewardship Economy, would build on stewardship, a 'duty of care' that values monetized and non-monetised products and services within the framing of rewards, framed as stewardship dividends, to farmers and other stewards of land and landscapes. Developing a stewardship economy as the framework for Indian agriculture would lead to a more resilient, equitable and optimistic future for Indian agriculture.
\end{abstract}

Agriculture in India is a success story-never have more people been fed nor more food been produced than right now. This success has come at a great cost: farmer indebtedness has mounted to unprecedented levels (NSO 2021); environmental and human health costs have been enormous (Dangar et al. 2021; Nelson et al. 2019); the annual rate of soil loss now far exceeds replacement rates (Sharda and Ojasvi 2016); and nutrition targets have been missed. Global trends are similar (Bene et al. 2019; Benton and Baily 2019; IPCC 2019; IPBES 2019). Building on Liebig's agricultural chemistry (Marchesi 2020), the Green Revolution model, hailed for consecutive successful harvests (Pingali 2012), sowed the seeds of the crises we face today.

\footnotetext{
* Deputy Director General (Research) at the World Agroforestry Centre (ICRAF) in Kenya, r.prabhu@,cgiar.org

Copyright (C) Prabhu 2022. Released under Creative Commons Attribution (C) NonCommercial 4.0 International licence (CC BY-NC 4.0) by the author.

Published by Indian Society for Ecological Economics (INSEE), c/o Institute of Economic Growth, University Enclave, North Campus, Delhi 110007.
}

ISSN: 2581-6152 (print); 2581-6101 (web).

DOI: https://doi.org/10.37773/ees.v5i1.612 
The need for more food grows with the human population. Some routes out of the food and agrarian crises depend on refined versions of the highinput agricultural models that characterized the Green Revolution. These include sustainable intensification (Royal Society 2009), precision agriculture (McBratney et al. 2005), and various other reforms (Chand 2020) that would likely intensify forms of industrialized agriculture.

If India continues to "industrialize" agriculture, creating "factories in the field" as McWilliams (1939) called them, social, environmental, and economic problems currently afflicting Indian agriculture will likely increase, as in the United States where small family farms are struggling, environmental issues abound, and industrialized farm labour faces social equity challenges (Costa and Martin 2019). In India, agriculture provides livelihoods for over half the population, and a shift to factory farming would likely result in a massive loss of livelihoods and social disruption. Formerly resilient landscapes, which are already degrading, will find themselves headed towards a dystopian future of accelerated vicious cycles of degradation with poorer livelihoods; concomitant erosion of local power, control, and democratic institutions; and uncertain land and tenure rights.

Industrialized agriculture's productivity and profitability model focuses almost entirely on efficiency gains and cost optimization, while the sustainability of input "sources" (e.g., fertilizers, pesticides, or water) or waste "sinks" (e.g., atmosphere, groundwater, or rivers) usually receives inadequate attention. Alternatives to factory farming models exist (TEEB 2018; IPCC 2019). In general, these are more explicit in their consideration of ecological principles and of the importance of natural and social capital, particularly at the local level (HLPE 2019). Framed as sets of principles, they offer a "low external/synthetic input" model that is likely to be more sustainable when measured against comprehensive metrics. There is now ample evidence that "low external input" approaches and practices such as agroforestry, natural farming, organic farming, and regenerative agriculture, along with the strengthening and upgrading of value chains, can improve incomes and environmental values in smallholder agriculture (ARASG 2021).

As we explain in this paper, reliance on the commodification of nature as the pathway to finding sustainable solutions is unlikely to succeed on its own. By "commodification", we mean focusing on nature's role solely as a provider of products or services that can be bought or sold in a market.

Adopting a "duty of care" relationship towards nature would reduce or reverse the commodification of nature without jeopardizing our ability to feed and sustain a burgeoning global population. Prabhu et al. (2021) 
propose the "stewardship economy" as the pathway to achieve this. They see stewardship as a deliberate and informed combination of solicitude, foresight, and skill -a marriage of practice and ethics, often born of experience and embedded in culture — that has visible and tangible impacts on landscapes and at the forest, farm, and community levels. Stewards, i.e., farmers, pastoralists, forest users, and fisherfolk are responsible for the commodities they produce while also exercising a duty of care towards the full range of services we derive from land and landscapes. They are both holders of rights and users of land and water resources. In short, stewards exercise and provide expression to a "duty of care" towards natural resources. In doing so, they also seek to influence policies equitably, fairly, and democratically, and similarly approach consumption patterns and behaviours that condition utilitarian relationships with nature.

Many of the possible instruments for facilitating an economic transition to stewardship are familiar in form. For instance, certification schemes such as those for timber, e.g., the Forest Stewardship Council, have been quite successful in recognizing stewardship, though less so in rewarding it, especially for smallholders. Payments for environmental services schemes have seen success, particularly with respect to water resources. Debt for nature swaps also encourages stewardship at larger scales. We can also add ecological fiscal transfers (EFTs) to this incomplete list; in 2015, India established the largest EFT scheme (Busch et al. 2020). All these schemes implicitly or explicitly aim to reward good stewardship, where the duty of care towards one service or product that is monetized is expected to deliver multiple co-benefits across others that are not monetized or commodified.

Prabhu et al. (2021) define a stewardship economy as "an equitable system of exchange that rewards those managing land sustainably for the goods and services we derive from those landscapes without disrupting the rights of people to food, nutrition, health, voice and decent livelihoods". Such an economy operates both within and outside markets as we know them, connecting stewards, direct and indirect, in nested and interacting landscapes. In a stewardship economy, as we understand it, there is a need to step beyond rewarding good management of produced commodities, as described above, to also considering the needs and welfare of the stewards. This implies, for instance, that the welfare of stewards in landscapes providing important but lower-priced commodities is not disadvantaged when compared to those producing higher-priced commodities, conditional to the value of cumulative services from those landscapes being comparable.

Framing land as a fixed asset as the market economy and balance sheets demand leads inevitably to the unsustainable outcomes we have now 
because market mechanisms are insufficient on their own, as Pigou and others have argued successfully in other contexts (Coase 1960). A reductive view of land and nature, reliance on commodification, and the consequent treatment of "externalities" drive the outcomes we see today. Let us consider the welfare of stewards in an agricultural commodity-dominated landscape, e.g., producing staples. Currently, markets have no realistic way of pricing staples so that they bear the true or full cost to the environment of unsustainable production. Any attempt to load the full costs of sustainable production onto staples within a purely market-driven solution would cause price rises that would likely affect the food-insecure poor disproportionally, causing more to go hungry, as Jayne et al. (2010) have shown for smallholder maize in Sub-Saharan Africa. As a result, in this example, the welfare of stewards in low-priced commodity landscapes is held hostage to the welfare of the urban poor and is therefore compromised. Markets for premium commodities offer more hope in this regard but tend to be far too "thin" to offer change at meaningful scales, as the degradation of shade coffee landscapes in the Western Ghats shows (Gaucherel et al. 2017). Considering poverty traps that can arise in the farming of renewable natural resources (forests, soils, water, and wildlife), Barrett (2008) suggests that "...intervention is essential if people are to escape and avoid persistent poverty" (36), as markets alone are inadequate. Beyond commodity and service markets, in many countries, and especially in forest-reliant communities, insecure or unclear property and tenure rights can additionally act as deterrents to investments in stewardship (Chopra and Gulati 1997; Reid et al 2005).

The commodification of nature often proceeds as an intensifying cycleextensive agriculture yields to mixed systems that in turn are replaced by monocultures as farmers seek market benefits from bulking and aggregation to improve their welfare. Losses in ecosystem services, resilience, and sustainability ensue because markets are neither intrinsically structured to ensure that a duty of care is exercised nor for the realization of equitable welfare outcomes. Recent reform efforts have sought to change this by pricing social and environmental goods more effectively, but with mixed results (Polasky et al. 2019).

If we are to reward farmers, forest users, and other "landscape actors" fairly for contributing to sustainable futures, we will need to look beyond markets as we know them today. Our search for a stewardship economy, as we propose here, leads us to suggest the need for "stewardship dividend", which would make up the difference between market-based income and the total income a steward needs to pursue their duty of care toward essential 
non-commodified products and services and simultaneously achieve equitable welfare outcomes.

Further, if producing an agricultural commodity without any negative externalities is taken at its full or true cost, and the price we can advantageously achieve in the market at which poor consumers can still affordably have access to essential commodities such as staples is its fair price, then in the case of most agricultural commodities, the true cost would exceed the fair price by a considerable margin. We postulate that the difference between the true and fair price of these commodities would approximate the "delta" that ensures nature remains resilient in the landscapes where these commodities are produced because stewards are investing efforts and knowledge in ensuring that key non-commodified ecosystem services are still being delivered without compromising their access to equitable welfare. The existence of "delta" or the stewardship dividend can therefore be postulated for any commodity or any agricultural landscape.

How would such a stewardship dividend be determined? Most efforts at determining the economic value of nature or ecosystem services depart from their perceived environmental importance (Dasgupta 2021; Polasky et al. 2019); while necessary, this is not sufficient to understand the true value of stewardship. Consider that nature exists as we find it because the people living there have so shaped it (Fletcher et al. 2021; Davis and Douglass 2021), and where it is "healthy", it is because stewards have left it so. This implies that our departure point for the determination of the stewardship dividend must simultaneously be based on 1) the needs and aspirations of the stewards, i.e., the incentives needed to support current behaviours or catalyse changes to it if necessary; 2) any economic value attributed to noncommodified products and services, from an environmental goals' perspective; and 3) the fair price of a commodity in the market. Consequently, it is not enough to focus on a farm or farming household as the unit of analysis, as ecosystem services are frequently emergent properties of larger geographical and temporal scales; thus, simultaneously considering landscape scales, decadal trends, and the collective action of people in those landscapes would be important. This will require more comprehensive metrics than those we currently use in agriculture so that stewardship performance is assessed fully. The availability of digital technologies - remote sensing through to social media-makes it possible now to track changes in key slow (e.g., soil erosion - Vagen and Winowiecki 2019) and fast (e.g., consumer preferences - Taylor 2019) variables at multiple, nested scales reliably and inclusively. This suggests that we can affordably estimate stewardship dividends, assess the performance 
of stewards against agreed metrics, and efficiently disburse rewards, e.g., as conditional cash transfers.

To pay for a transition to a stewardship economy, as a first step, we could reform and repurpose subsidies shown to have perverse impacts (Ramaswami 2019; Chand 2020) in addition to investments to replace or compensate for the loss of ecosystem infrastructure due to agriculture. In India, Ramaswami (2019) has estimated that $21 \%$ of farm income is derived from subsidies alone, already a substantial financial corpus for this purpose. Additionally, investments in replacing or compensating for ecological infrastructure (e.g., Chakrabarti et al. 2019; Chand 2017) along with those facilitating green development would greatly increase the financial latitude. Conservatively, these funds could offer each farming household practising stewardship an annual stewardship dividend equivalent to at least one-third of their income, before income gains of adopting better farm and land management are added. Significant improvements to welfare while transitioning to sustainable agriculture are therefore eminently possible for Indian farmers in a stewardship economy. Challenges remain such as ensuring that these transfers reach those they are intended for efficiently and effectively. This will likely include securing and clarifying rights including common property or communal rights that are essential to the effective exercise of stewardship responsibilities.

While much of the understanding and many of the tools required to transition to a stewardship economy already exist in some form, there is still a need for more work. For instance, innovative finance, investment, and performance management arrangements will need to be developedcapable of reaching through complex social organizations and networks in time. The design process for this renaissance of Indian agriculture must be inclusive, equitable, and democratic to lead to the behaviour and attitude changes sought.

We need a more resilient, equitable, and optimistic future for Indian agriculture. Accepting that a duty of care must pervade all of agriculture, forest, and land management is the key step in this direction. India's agricultural sector is crying out for this kind of innovation and reinvention. Nature is more than products; it also provides immeasurable services. People are not just producers; they are also carers. It is high time we recognize, build on, and reward this. 


\section{REFERENCES}

ARASG. 2021. "Regenerative Agriculture: An Opportunity for Businesses and Society to Restore Degraded Land in Africa." Africa Regenerative Agriculture Study Group.

https://www.iucn.org/sites/dev/files/regnererative agriculture in africa report 2021.pdf

Barrett, Christopher B. 2008. "Poverty Traps and Resource Dynamics in Smallholder Agrarian Systems." In Economics of Poverty, Environment and Natural Resource Use, edited by A Ruijs and R Dellink, pp 17-40. Verlag: Springer.

Béné, Christophe, Peter Oosterveer, Lea Lamotte, Inge D Brouwer, Stef de Haan, Steve D Prager, Elise F Talsma, and Colin K Khoury. 2019. "When Food Systems Meet Sustainability: Current Narratives and Implications for Actions." World Development 113: 116-130. https://doi.org/10.1016/j.worlddev.2018.08.011.

Benton, Tim G and Rob Bailey. 2019. "The Paradox of Productivity: Agricultural Productivity Promotes Food System Inefficiency." Global Sustainability 2. https://doi.org/10.1017/sus.2019.3

Busch, Jonah, Avani Kapur, and Anit Mukerji. 2020. "Did India's Ecological Fiscal Transfers Incentivize State Governments to Increase Their Forestry Budgets?" Environmental Research Communications 2 (3): 031006. https://doi.org/10.1088/2515-7620/ab817c

Chakrabarti, Suman, Mohammed Tajuddin Khan, Avinash Kishore, Devesh Roy, and Samuel P Scott. 2019. "Risk of Acute Respiratory Infection from Crop Burning in India: Estimating Disease Burden and Economic Welfare from Satellite and National Health Survey Data For 250000 Persons." International Journal of Epidemiology 48 (4): 1113-1124. https://doi.org/10.1093/ije/dyz022

Chand, Ramesh. 2017. "Doubling Farmers Income." Indian Journal of Agricultural Economics 72 (1).

Chand, Ramesh. 2020. "Addressing Agrarian Distress: Sops Versus Development." In Planning in the 20th Century and Beyond: India's Planning Commission and the NITI Aayog, edited by Santosh Mehrotra and Sylvie Guichard, 110-131. Cambridge: Cambridge University Press. https://doi.org/10.1017/9781108859448.006

Chopra, Kanchan and Sumeet Gulati. 1997. "Environmental Degradation and Population Movements: The Role of Property Rights." Environmental and Resource Economics 9: 383-408. https://doi.org/10.1023/A:1026455024293.

Coase, Ronald H. 1960. "The Problem of Social Cost." The Journal of Law and Economics 3 (1): 1-44. https://doi.org/10.1086/466560

Costa, Daniel and Philip Martin. 2019. "OECD Highlights Temporary Labor Migration. Almost as Many Guestworkers as Permanent Immigrants." Economic Policy Institute. https://www.epi.org/blog/oecd-highlights-temporary-labormigration-almost-as-many-guestworkers-as-permanent-immigrants $/$. 
Dangar, Swarup, Akarsh Asoka, and Vimal Mishra. 2021. "Causes and Implications of Groundwater Depletion in India: A Review." Journal of Hydrology 596: 126103. https://doi.org/10.1016/i.jhydrol.2021.126103

Dasgupta, Partha. 2021. "The Economics of Biodiversity." The Dasgupta Review. London, UK: HM Treasury.

Davis, Dylan S and Kristina Douglass. 2021. "Remote Sensing Reveals Lasting Legacies of Land-Use by Small-Scale Foraging Communities in the Southwestern Indian Ocean." Frontiers in Ecology and Evolution. https://www.frontiersin.org/articles/10.3389/fevo.2021.689399/full.

Dorin, Bruno. 2021. "Theory, Practice and Challenges of Agroecology in India", International Journal of Agricultural Sustainability: 1-15. https://doi.org/10.1080/14735903.2021.1920760

Fletcher, Michael-Shawn, Rebecca Hamilton, Wolfram Dressler, and Lisa Palmer. 2021. "Indigenous Knowledge and the Shackles of Wilderness." Proceedings of the National Academy of Sciences $118 \quad$ (40): 2022218118. https://doi.org/10.1073/pnas.2022218118

Gaucherel, Cedric, Julie Alet, and Claude A Garcia. 2017. "Coffee Monoculture Trends in Tropical Agroforested Landscapes of Western Ghats (India)." $\begin{array}{lllll}\text { Environmental } & \text { Conservation } & 44 & \text { (2): } & \text { 183-190. }\end{array}$ https://doi.org/10.1017/S0376892916000394

HLPE. 2019. "Agroecological and Other Innovative Approaches for Sustainable Agriculture and Food Systems that Enhance Food Security and Nutrition." A Report by the High Level Panel of Experts on Food Security and Nutrition of the Committee on World Food Security. Rome: FAO. http://www.fao.org/3/ca5602en/ca5602en.pdf.

IPBES. 2019. "Summary for Policymakers of the Global Assessment Report on Biodiversity and Ecosystem Services of the Intergovernmental Science-Policy Platform on Biodiversity and Ecosystem Services." Sandra Díaz, Josef Settele, Eduardo Brondizio, Hien T Ngo, Alexander Pfaff, Stephen Polasky, John Agard, Almut Arneth, Patricia Balvanera, Kate A Brauman, et al. (eds). Bonn, Germany: IPBES Secretariat. https://doi.org/10.1126/science.abb6019

IPCC. 2019. "IPCC Special Report on Climate Change, Desertification, Land Degradation, Sustainable Land Management, Food Security, and Greenhouse Gas Fluxes in Terrestrial Ecosystems." Summary for Policymakers. The Intergovernmental Panel on Climate Change. In press. https://www.ipcc.ch/srccl/ Jayne, TS, David Mather, Elliot Mghenyi. 2010. "Principal Challenges Confronting Smallholder Agriculture in Sub-Saharan Africa." World Development 38 (10): 1384-1398. https://doi.org/10.1016/j.worlddev.2010.06.002

Marchesi, Greta. 2020. "Justus von Liebig Makes the World: Soil Properties and Social Change in the Nineteenth Century." Environmental Humanities 12 (1): 205226. https://doi.org/10.1215/22011919-8142308 
McBratney, Alex, Brett Whelan, Tihomir Ancev, and Johan Bouma. 2005. "Future Directions of Precision Agriculture." Precision Agriculture 6: 7-23. https://doi.org/10.1007/s11119-005-0681-8

McWilliams, Carey. 1939. Factories in the Field. The Story of Migratory Farm Labor in California. Reprint 2000. California, USA: University of California Press. https://doi.org/10.1525/9780520925182

Nelson, Ann Raeboline Lincy Eliazer, Kavitha Ravichandran, and Usha Antony. 2019. "The Impact of the Green Revolution on Indigenous Crops of India." Journal of Ethnic Foods 6 (1): 8. https://doi.org/10.1186/s42779-019-0011-9

National Statistical Office (NSO). 2021. "Situation Assessment of Agricultural Households and Land Holdings of Households in Rural India, 2019." New Delhi: National Statistics Office, Ministry of Statistics and Programme Implementation, Government of

India.

https://www.pib.gov.in/PressReleasePage.aspx?PRID=1753856

Pingali, Prabhu L. 2012. "Green Revolution: Impacts, Limits, and the Path Ahead." Proceedings of the National Academy of Sciences 109 (31): 2302-12308. https://doi.org/10.1073/pnas.0912953109

Polasky, Stephen, Catherine L Kling, Simon A Levin, Stephen R Carpenter, Gretchen C Daily, Paul R Ehrlich, Geoffrey M Heal, and Jane Lubchenco. 2019. "Role of Economics in Analyzing the Environment and Sustainable Development." Proceedings of the National Academy of Sciences 116 (12): 5233-5238. https://doi.org/10.1073/pnas.1901616116

Prabhu, Ravi, Steven Lawry, and John Colmey. 2021. "Creating a New Relationship with Nature Through a 'Stewardship Economy'." Forests News. https:/ / forestsnews.cifor.org/74803/creating-a-new-relationship-with-naturethrough-a-stewardship-economy? fnl=en.

Ramaswami, B. 2019. "Agricultural Subsidies." Study Prepared for the XV Finance Commission. New Delhi: Indian Statistical Institute.

Reid, Walter V, Harold A Mooney, Doris Capistrano, Stephen R Carpenter, Kanchan Chopra, Angela Cropper, Partha Dasgupta, Rashid Hassan, Rik Leemans, Robert M May, et al. 2005. "Millennium Ecosystem Assessment: Ecosystems and Human Well-being." Synthesis. Island Press, Washington, DC.

Royal Society. 2009. Reaping the Benefits: Science and the Sustainable Intensification of Global Agriculture. London, UK: Royal Society. https://royalsociety.org/topics-policy/publications/2009/reaping-benefits/

Sharda, Vishwa N and Prabhat R Ojasvi. 2016. "A Revised Soil Erosion Budget for India: Role of Reservoir Sedimentation and Land-Use Protection Measures." Earth Surface Processes and Landforms 41: 2007-2023. https://doi.org/10.1002/esp.3965

The Economics of Ecosystems and Biodiversity (TEEB). 2018. "Scientific and Economic Foundations Report." TEEB for Agriculture \& Food: Scientific and Economic Foundations. Geneva: UN Environment. http://teebweb.org/ourwork/agrifood/reports/scientific-economic-foundations/. 
Ecology, Economy and Society-the INSEE Journal [14]

Taylor, Bradley. 2019. "Understanding Consumer Preferences from Social Media Data." NIM Marketing Intelligence Review 11 (2): 48-53. https://doi.org/10.2478/nimmir-2019-0016

Vågen, Tor-Gunnar and Leigh Ann Winowiecki. 2019. "Predicting the Spatial Distribution and Severity of Soil Erosion in the Global Tropics using Satellite Remote Sensing." Remote Sensing $11 \quad$ (15): 1800. https://doi.org/10.3390/rs11151800. 